\title{
LETTERS
}

\section{Screening for chlamydia and gonorrhea in primary care in populations with low prevalence}

I read the new recommendations on primary care screening for chlamydia and gonorrhea with interest, but I wanted to highlight an issue not addressed in the article. ${ }^{1}$

Although most nucleic acid amplification tests used for diagnosis of chlamydia and gonorrhea in Canada have excellent clinical sensitivity and specificity (> 95\%), ${ }^{2}$ they may still generate false-positive results when used in a population with low prevalence of these diseases. Consider the example of female vaginal swabs taken for chlamydia testing in a population with a $1.5 \%$ prevalence of chlamydia (within the estimate indicated in the screening recommendations). Using a test with $97.2 \%$ sensitivity and $98.5 \%$ specificity, ${ }^{3}$ the positive and negative predictive values are $49.7 \%$ and $99.9 \%$, respectively. That means the chance that a positive result is a false positive is greater than $50 \%$.
The concern with false positives drops as prevalence increases; the same test in a population with $10 \%$ prevalence of chlamydia has a positive predictive value of $87.8 \%$, so only roughly 1 in 10 positive results would be a false positive. In other words, test performance is better in higher-risk populations.

Widespread testing for chlamydia and gonorrhea can help to reduce disease transmission and complications. However, health care providers should be aware that with expanded screening in a lowprevalence population, they will see falsepositive results, which may cause anxiety for patients and their partners and could lead to unnecessary interventions. Repeat testing should be considered if a falsepositive result is suspected based on a patient's individual history; a subsequent negative result is reassuring, given the high negative predictive value of nucleic acid amplification tests in this context.

\section{Diana Whellams MD MPH}

Medical microbiologist, LifeLabs, Surrey, BC
- Cite as: CMAJ 2021 August 23;193:E1307. doi: $10.1503 / \mathrm{cmaj} .79560$

\section{References}

1. Moore A, Traversy G, Reynolds DL, et al. Recommendation on screening for chlamydia and gonorrhea in primary care for individuals not known to be at high risk. CMAJ 2021;193:E549-59.

2. Chernesky M, Jang D, Gilchrist J, et al. Head-tohead comparison of second-generation nucleic acid amplification tests for detection of Chlamydia trachomatis and Neisseria gonorrhoeae on urine samples from female subjects and selfcollected vaginal swabs. J Clin Microbiol 2014;52: 2305-10.

3. Aptima Combo 2 Assay (Panther System) product insert (502446 Rev 003). Mississauga, ON: Hologic; 2017. Available at www.hologic.com/ sites/default/files/package-insert/502446-IFU-PI _003_01.pdf (accessed 2021 June 15).

\section{Competing interests: None declared.}

Content licence: This is an Open Access article distributed in accordance with the terms of the Creative Commons Attribution (CC BY-NC-ND 4.0) licence, which permits use, distribution and reproduction in any medium, provided that the original publication is properly cited, the use is noncommercial (i.e., research or educational use), and no modifications or adaptations are made. See: https://creativecommons. org/licenses/by-nc-nd/4.0/ 